\title{
Persistence of the Host-Selective Toxin Ptr ToxB in the Apoplast
}

\author{
Melania Figueroa, Viola A. Manning, lovanna Pandelova, and Lynda M. Ciuffetti \\ Department of Botany and Plant Pathology and Center for Genome Research and Biocomputing, Oregon State University, \\ Corvallis, OR 97331 , U.S.A.
}

Submitted 4 May 2015. Accepted 28 May 2015.

\begin{abstract}
The necrotrophic fungus Pyrenophora tritici-repentis is responsible for the disease tan spot of wheat. Ptr ToxB (ToxB), a proteinaceous host-selective toxin, is one of the effectors secreted by $P$. tritici-repentis. ToxB induces chlorosis in toxinsensitive wheat cultivars and displays characteristics common to apoplastic effectors. We addressed the hypothesis that ToxB exerts its activity extracellularly. Our data indicate that hydraulic pressure applied in the apoplast following ToxB infiltration can displace ToxB-induced symptoms. In addition, treatment with a proteolytic cocktail following toxin infiltration results in reduction of symptom development and indicates that ToxB requires at least $8 \mathrm{~h}$ in planta to induce maximum symptom development. In vitro assays demonstrate that apoplastic fluids extracted from toxin-sensitive and -insensitive wheat cultivars cannot degrade ToxB. Additionally, ToxB can be reisolated from apoplastic fluid after toxin infiltration. Furthermore, localization studies of fluorescently labeled ToxB indicate that the toxin remains in the apoplast in toxin-sensitive and -insensitive wheat cultivars. Our findings support the hypothesis that ToxB acts as an extracellular effector.
\end{abstract}

Plant pathogens secrete a wide variety of effectors (i.e., proteins and secondary metabolites) that play a major role in establishment of the pathogen and development of disease (Ciuffetti et al. 2010; Hogenhout et al. 2009; Jones and Dangl, 2006; Win et al. 2012). Effectors can act inside of the host cell (intracellularly) or remain in the plant apoplastic space, where they can act extracellularly (Hogenhout et al. 2009; Manning and Ciuffetti, 2005; Rep 2005; Stergiopoulos and de Wit 2009; Win et al. 2012). In this context, the outcome of host-pathogen interactions (susceptibility or resistance) is at least partly dictated by physiological and biochemical events that take place in the apoplast and plasma membrane-cell wall interface.

The necrotrophic fungus Pyrenophora tritici-repentis (Died.) Drechs. (anamorph: Drechslera tritici-repentis (Died.) Shoemaker) is the causal agent of tan spot of wheat (Triticum aestivum L.), a disease of significant economic impact worldwide due to yield

Current address for M. Figueroa: Department of Plant Pathology and the Stakman-Borlaug Center for Sustainable Plant Health, University of Minnesota, St. Paul, MN, 55108, U.S.A

Corresponding author: L. M. Ciuffetti;

E-mail: ciuffetL@science.oregonstate.edu

*The $\boldsymbol{e}$-Xtra logo stands for "electronic extra" and indicates that one supplementary figure is published online.

() 2015 The American Phytopathological Society losses in wheat production (De Wolf et al. 1998; Lamari et al. 1995; Murray and Brennan 2009; Perello et al. 2003; Strelkov and Lamari 2003). The infection of $P$. tritici-repentis involves the development of necrotic or chlorotic symptoms, or both, which are caused by the secretion of host-selective toxins (HST) (Ballance et al. 1989; Brown and Hunger 1993; Lamari et al. 1995; Martinez et al. 2001; Orolaza et al. 1995; Strelkov et al. 1999; Tomas et al. 1990; Tuori et al. 1995; Zhang et al. 1997). HST are effectors that induce cell death in specific host genotypes and, therefore, act as pathogenicity or virulence factors in several host-pathogen interactions (Ciuffetti et al. 1997, 2010; Faris et al. 2013; Friesen et al. 2008; Walton 1996; Wolpert et al. 2002).

To date, two proteinaceous HST have been characterized in P. tritici-repentis, Ptr ToxA (ToxA), which induces necrosis (Ballance et al. 1989; Ciuffetti et al. 1997; Tomas et al. 1990; Tuori et al. 1995), and Ptr ToxB (ToxB), which triggers chlorosis (Ciuffetti et al. 1998; Martinez et al. 2001; Orolaza et al. 1995; Strelkov et al. 1999). Given that ToxA was the first identified proteinaceous HST, significant progress has been made toward characterizing the site and mode of action of this toxin (Ciuffetti et al. 2010). Sensitivity to ToxA is dictated by internalization of the toxin into sensitive wheat mesophyll cells, a process that appears to be mediated by endocytosis (V. A. Manning and L. M. Ciuffetti, unpublished data) and depends on the presence of an Arg-Gly-Asp (RGD) motif on a solventexposed loop of ToxA (Ciuffetti et al. 2010; Manning and Ciuffetti 2005, 2008; Sarma et al. 2005). The site and mode of action of ToxB is not well-characterized, although data indicates that, similar to ToxA, ToxB also affects chloroplast function (Kim and Strelkov 2007; Pandelova et al. 2012). Unlike ToxA, ToxB does not contain an RGD motif and comparisons with other protein sequences available in public databases have not identified functional motifs that could aid in the characterization of the ToxB site and mode of action.

ToxB (261 bp) encodes an 87-amino acid (aa) preprotein that produces a 64-aa mature protein following cleavage of the secretory signal peptide (Figueroa Betts et al. 2011; Martinez et al. 2001; Strelkov et al. 2006). Nonpathogenic P. triticirepentis isolates have been found to contain a ToxB homolog, toxb (Martinez et al. 2004; Strelkov et al. 2006). ToxB and toxb differ in 13 aa and the toxb sequence is 1 aa longer than ToxB (Martinez et al. 2004; Strelkov et al. 2006). According to mass spectrometry analysis, the molecular mass of ToxB and toxb is 6.5 and $6.6 \mathrm{kDa}$, respectively (Figueroa Betts et al. 2011). Infiltrations of either native or heterologously expressed ToxB in Pichia pastoris demonstrated that ToxB triggers chlorosis only in ToxB-sensitive wheat cultivars, whereas toxb does not induce any symptoms in either ToxB-sensitive or insensitive wheat cultivars (Andrie and Ciuffetti 2011; Figueroa Betts et al. 2011; Strelkov et al. 1999). 
Effectors that exert their functions in the extracellular space are typically small molecules with a relatively high number of cysteine residues that often form disulfide bridges (Joosten and de Wit 1999; Kamoun 2006; Rep 2005; Stergiopoulos and de Wit 2009; Thomma et al. 2005). Such structural properties allow for a compact protein conformation that contributes to survival of these effectors in the acidic (pH 5 to 6) and proteaserich plant apoplastic space (Felle 1998; Hückelhoven 2007). Mass spectrometry analysis and nuclear magnetic resonance (NMR) structural analysis demonstrate that the four cysteine residues present in the sequence of ToxB form two disulfide bridges (Figueroa Betts et al. 2011; Nyarko et al. 2014). The importance of the structural context of these disulfide bridges in ToxB is indicated by the reduction of chlorosis-inducing activity that results from the replacement of valine3, a residue next to cysteine2, with threonine (Figueroa Betts et al. 2011). Structural data also indicate that ToxB adopts a tightly folded conformation (Nyarko et al. 2014). Thus, ToxB displays properties typical of an apoplastic effector. Several experimental approaches used in this study suggest that ToxB remains in the apoplast and acts as an extracellular effector.

\section{RESULTS}

Movement of ToxB in the plant apoplast.

Manifestation of toxin-induced symptoms and their development could be a reflection of their ability to interact with

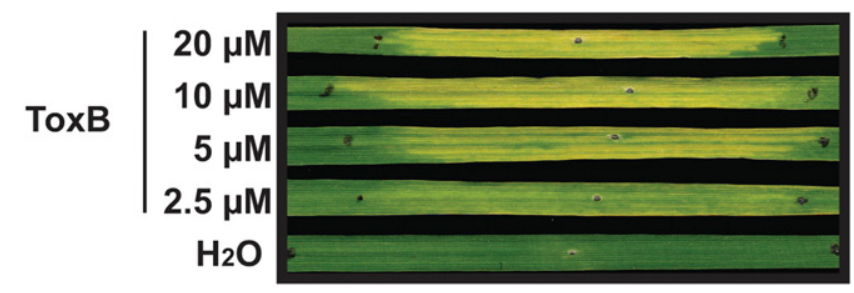

Fig. 1. Bioassay of ToxB-sensitive leaves infiltrated with a range of ToxB concentrations. Concentrations are indicated on the left. 'Katepwa' was used as the ToxB-sensitive wheat cultivar. Black dots define the toxin infiltration zone. $\mathrm{H}_{2} \mathrm{O}$ was infiltrated as a negative control. high- or low-affinity binding sites on the plant cell plasma membrane. The presence of a high-affinity receptor would result in a rapid sequestration of the toxin at the point of infiltration, whereas the absence of a high-affinity receptor would allow for an even distribution of the toxin-containing solution throughout the infiltration zone. For instance, when decreasing concentrations of ToxA are infiltrated into toxinsensitive leaves, the intensity of the necrotic symptoms does not decrease, only the size of the toxin-affected area is reduced. It has been posited that ToxA has an abundant highaffinity plant cell receptor, due to the observation that the area of toxin activity is restricted by the concentration of toxin applied (Manning et al. 2008). In contrast, when decreasing concentrations of ToxB are infiltrated into toxin-sensitive leaves, the intensity of the chlorosis decreases but the size of the affected leaf area remains the same (Fig. 1). This suggests that, unlike ToxA, ToxB does not bind to a high-affinity receptor.

To further test if ToxB lacks a high-affinity receptor, we examined whether hydraulic pressure could displace ToxBinduced symptoms beyond the initial toxin infiltration zone. At several time points following ToxB infiltration, $\mathrm{H}_{2} \mathrm{O}$ was infiltrated into the original toxin treatment zone and $1 \mathrm{~cm}$ beyond, and the development of chlorotic symptoms was monitored throughout the $\mathrm{H}_{2} \mathrm{O}$ infiltration zone (Fig. 2A). Infiltration of ToxB at high concentrations can sometimes result in development of chlorosis outside of the treatment zone toward the tip of the leaf but not the base (Fig. 2B, leaf a, the left flank represents the base of the leaf, whereas the right flank represents the tip of the leaf). The treatment with $\mathrm{H}_{2} \mathrm{O}$ after 1 and $3 \mathrm{~h}$ post-toxin infiltration (hpi) resulted in obvious chlorotic symptom development beyond the toxin infiltration zone and into both the right and left flank of the toxin infiltration zone in the $\mathrm{H}_{2} \mathrm{O}$ infiltration zone (Fig. 2B, leaves b and c compared with leaf a). Similarly, treatment with $\mathrm{H}_{2} \mathrm{O}$ at 6 and 24 hpi induced symptoms beyond the toxin infiltration zone, although to a lesser extent than earlier time points (Fig. 2B, leaves d and e compared with leaf a). The displacement of ToxB symptoms beyond the toxin infiltration zone supports the absence of a high-affinity receptor for ToxB and indicates that a significant amount of ToxB remains active in the apoplastic space for several hours.

A

Step 1

ToxB infiltration zone

Wheat leaf

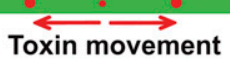

Step 2
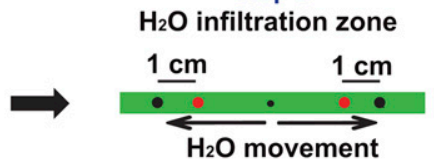

B

Treatments

\begin{tabular}{l|l}
\hline Step 1 (ToxB) & Step $2\left(\mathrm{H}_{2} \mathrm{O}\right)$ \\
\hline
\end{tabular}

\begin{tabular}{l|l}
+ & none \\
+ & $1 \mathrm{hpi}$ \\
+ & $3 \mathrm{hpi}$ \\
+ & $6 \mathrm{hpi}$ \\
+ & $24 \mathrm{hpi}$ \\
+ & none
\end{tabular}
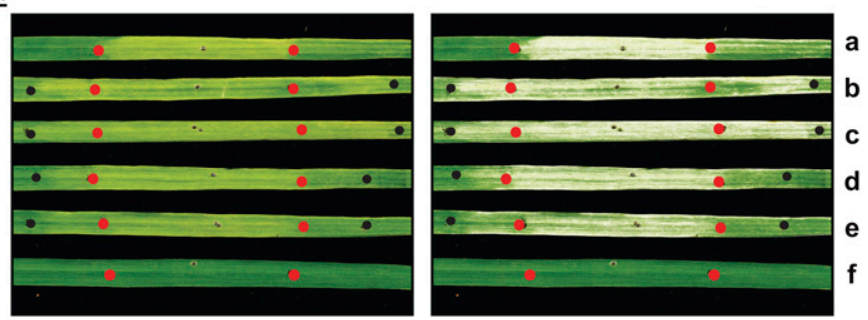

Fig. 2. Hydraulic pressure displaces ToxB symptom development. A, Experimental design. Step 1, infiltration with either $10 \mu \mathrm{M}$ ToxB or $\mathrm{H}_{2} \mathrm{O}$ alone (red dots). Step 2, treatment of the toxin infiltration zone with $\mathrm{H}_{2} \mathrm{O}$ at different time points (hours post-toxin infiltration [hpi]). Treatment with $\mathrm{H}_{2} \mathrm{O}$ extends to at least $1 \mathrm{~cm}$ beyond the toxin infiltration zone (black dots). B, Bioassay of ToxB-induced symptom development after hydraulic pressure treatments. Treatments include infiltration of $\mathrm{H}_{2} \mathrm{O}(-)$ as negative control or ToxB (+) alone (Step 1) or followed by $\mathrm{H}_{2} \mathrm{O}$ (Step 2) at 1, 3, 6, and 24 hpi. Bioassays were performed in the toxinsensitive wheat cultivar Katepwa. To ease visualization of the ToxB-induced symptoms (left panel), chlorotic areas in the leaves were colorized white (right panel).

Vol. 28, No. $10,2015 / 1083$ 


\section{Stability of ToxB in the plant apoplast.}

ToxB is highly resistant to heat (Kim and Strelkov 2007) and organic compounds (Orolaza et al. 1995; Strelkov et al. 1999), which suggests that ToxB has the structural stability to withstand harsh conditions, such as those characteristic of the plant apoplast. For ToxB to exert its activity in the apoplast, it would require a high degree of resistance to apoplastic proteases. By extension, one possible explanation for the lack of biological activity of toxb could be its sensitivity to apoplastic proteases. In vitro digestion assays were used to examine the resistance of ToxB and toxb to apoplastic extracts from toxin-sensitive (Katepwa) or -insensitive (Auburn) wheat cultivars. Experiments conducted in our laboratory suggest that ToxA, which has an intracellular site of action, is sensitive to apoplastic proteases. Therefore, His-ToxA was included in the digestion assays as a positive control of the apoplastic fluid (AF) proteolytic activity. The proteolytic effect of the AF on the different toxins was evaluated by silver -stained sodium dodecyl sulfate-polyacrylamide gel electrophoresis (SDS-PAGE) and Western blot analyses. On SDS-PAGE, ToxB resolves as a single band (Fig. 3A, lanes 2, 4, 6), toxb resolves as two bands (approximately 14 and $6.5 \mathrm{kDa}$ ) (Fig. 3B, lanes 2, 4, 6) (Andrie and Ciuffetti 2011; Figueroa Betts et al. 2011), and the multiple proteins present in AF resolve as defined bands and a smear throughout the lane (Fig. 3A and B, lanes 3, 5, 7). Based on the presence and intensity of the ToxB bands on SDS-PAGE and
Western blot analyses (data not shown), it was concluded that treatment of ToxB for $1 \mathrm{~h}$ (Fig. 3A, lanes 2 compared with 3 ), $6 \mathrm{~h}$ (Fig. 3A, lanes 4 compared with 5), and $24 \mathrm{~h}$ (Fig. 3A, lanes 6 compared with 7 and $C$, top panel) with $\mathrm{AF}$ extracted from the toxin-sensitive cultivar did not degrade ToxB. This was also true for the approximately $6.5-\mathrm{kDa}$ band that represents toxb (Fig. 3C, middle panel) but could not be determined for the approximately $14-\mathrm{kDa}$ band that was masked by the proteins present in the AF (Fig. 3B). Both ToxB and toxb were also resistant to AF extracted from a toxin-insensitive wheat cultivar (Supplementary Fig. S1). Given the amount of proteins in the $\mathrm{AF}$ and the molecular mass of His-ToxA (19 kDa), it was difficult to determine in a silver-stained SDS-PAGE whether HisToxA had been degraded (data not shown). However, Western blot analysis clearly showed that His-ToxA was completely degraded following exposure to AF for $1 \mathrm{~h}$ (Fig. 3C, bottom panel). These results indicate that ToxB and toxb are highly resistant to apoplastic proteases from toxin-sensitive and -insensitive wheat cultivars. Moreover, the lack of activity of toxb does not appear to be due to its degradation by plant apoplastic proteases.

As indicated above, results demonstrate that ToxB symptom development could be displaced by $\mathrm{H}_{2} \mathrm{O}$ infiltration as late as $24 \mathrm{hpi}$, which suggests that ToxB persists in the apoplast for an extended period of time. To confirm this, we examined whether ToxB could be recovered from AF extracted from
A

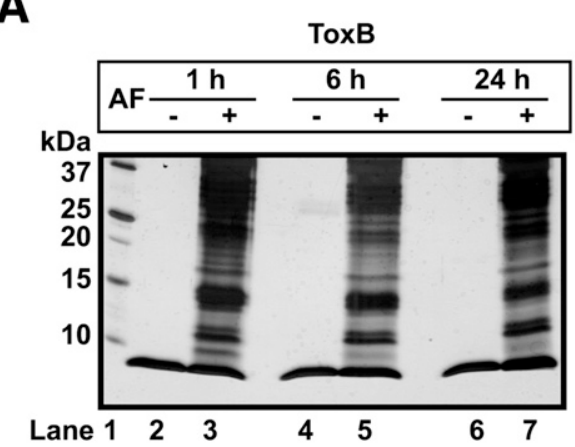

C

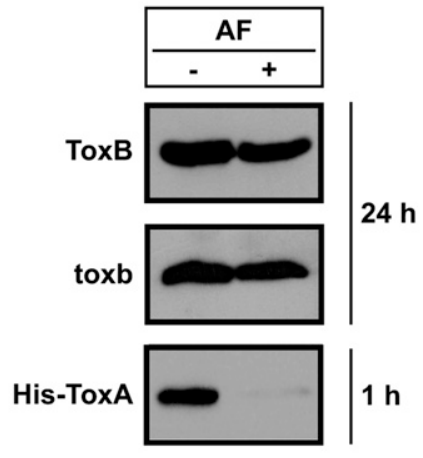

B

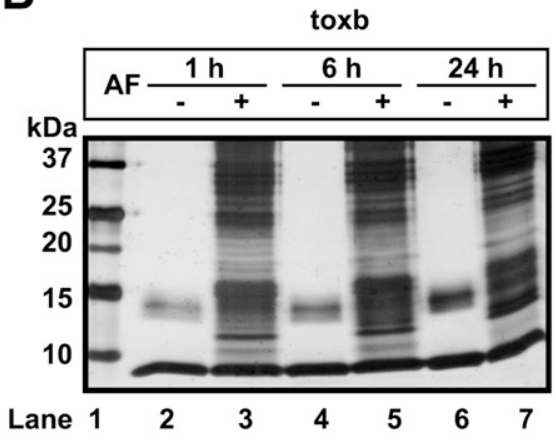

D
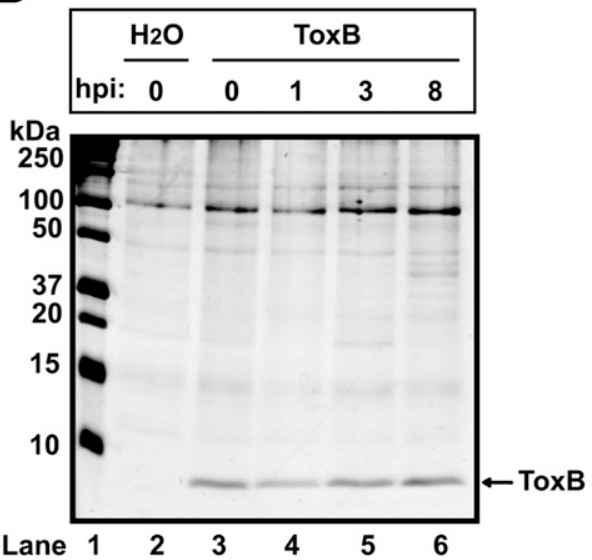

Fig. 3. Stability of ToxB in the plant apoplast. A, In vitro treatment of ToxB or $\mathbf{B}$, inactive toxb with apoplastic fluid (AF) isolated from the toxin-sensitive wheat cultivar Katepwa. Equal amounts of protein were incubated with $\mathrm{H}_{2} \mathrm{O}(-)$ or $\mathrm{AF}(+)$ for 1,6 , and $24 \mathrm{~h}$. Proteins were resolved by sodium dodecyl sulfatepolyacrylamide gel electrophoresis (SDS-PAGE) and were detected by silver stain. C, Western blot analysis of ToxB (top panel), toxb (middle panel) and Histagged ToxA (bottom panel) treated with $\mathrm{H}_{2} \mathrm{O}(-)$ or $\mathrm{AF}(+)$ isolated from the toxin-sensitive wheat cultivar Katepwa. Anti-Ptr ToxB and anti-Ptr ToxA antisera were used to probe immunoblots for ToxB/toxb and His-tagged ToxA, respectively. D, Extraction of AF from toxin-sensitive leaves previously infiltrated with ToxB. Leaves were treated with $\mathrm{H}_{2} \mathrm{O}$ or $10 \mu \mathrm{M}$ ToxB. AF was extracted at $0,1,3$, and $8 \mathrm{~h}$ post-toxin infiltration (hpi). Equal amounts of total protein were resolved by SDS-PAGE and were detected by silver stain. The arrow indicates the protein band corresponding to ToxB. Sizes of a set of molecular mass (kDa) standards are indicated on the left of SDS-PAGE gels. 
leaves infiltrated with the toxin. ToxB was infiltrated into toxinsensitive leaves, AF was extracted at $0,1,3$, and $8 \mathrm{hpi}$, and extracts were analyzed for the presence of ToxB by silverstained SDS-PAGE and Western blot analyses. A ToxB band of similar intensity was detected in the AF extracted at each time point (Fig. 3D, lanes 3 to 6 , arrow), suggesting that the amount of toxin extracted was similar among those time points.

\section{Protease treatment of ToxB-infiltrated leaves.}

Given that ToxB is tolerant to apoplastic proteases and that in vitro studies have shown that ToxB is more resistant than ToxA to proteolysis by proteinase $\mathrm{K}$ and trypsin (M. Figueroa and L. M. Ciuffetti, unpublished data), we sought to determine if infiltration of a strong protease could degrade ToxB and if infiltration of this protease into the apoplast following ToxB treatment could reduce or abolish ToxB-induced symptoms. Pronase is a nonspecific protease and contains a mixture of different modes of proteolytic activity (e.g., neutral protease, chymotrypsin, trypsin, carboxypeptidase, aminopeptidase) (Narahashi 1970; Trop and Birk 1970). We found that in vitro treatment of ToxB with $1 \mathrm{mg}$ of pronase per milliliter for $30 \mathrm{~min}$ at room temperature was sufficient to completely degrade the toxin (Fig. 4A). Furthermore, infiltration of pronase into ToxB-sensitive plant leaves did not cause any symptoms (Fig. 4C, leaf a compared with b).

Toxin-sensitive wheat leaves were infiltrated with ToxB alone or ToxB followed by pronase treatment (Fig. 4B). To reduce the risk of displacing the toxin during protease treatment, pronase was infiltrated at the left and right flanking sides of the toxin infiltration zone. A total chlorophyll quantification assay was used to estimate ToxB-induced chlorosis. Pronase treatment at 1, 3, 6, and 8 hpi reduced the intensity of ToxBinduced chlorosis, and the amount of total chlorophyll extracted from these leaves was significantly different than treatment with ToxB alone (Fig. 4C and D, leaf c compared with d, e, f, g). In contrast, pronase treatment at 24 and 48 hpi did not significantly affect symptom development or chlorophyll content (Fig. 4C and D, leaf c compared with h and i). These data indicate that the reduction in chlorosis was time-dependent, i.e., the greatest reduction of symptoms occurred when pronase was applied at 1 and $3 \mathrm{hpi}$. Together, these results suggest that ToxB localizes to the apoplast and requires at least $8 \mathrm{~h}$ to trigger maximum symptom development.

\section{Localization of ToxB in the apoplast.}

While ample evidence suggests that ToxB persists in the apoplast of treated leaves for at least $24 \mathrm{~h}$ and data show that apoplastic persistence is required for at least $8 \mathrm{~h}$ for full toxin activity, it is not known whether ToxB is internalized into sensitive or insensitive cells. Similar to the approach used to characterize an intracellular site of action of ToxA (Manning et al. 2010), we sought to use the Barley stripe mosaic virus (BSMV)-mediated transient systemic expression system to express ToxB intracellularly. The interpretation of these results was not straightforward (data not shown); therefore, we attempted to answer this question by fluorescently labeling ToxB with the green fluorescent dye Alexa Fluor 488 (ToxB488 ) and monitoring localization of the fluorescent protein in live wheat leaves with confocal microscopy (Fig. 5). ToxA, which is known to be localized to mesophyll cell cytoplasm and chloroplasts (Manning and Ciuffetti 2005), labeled with Alexa Fluor 488 (ToxA-488) and free Alexa Fluor 488 were used as controls. ToxB-488 was as active as unlabeled ToxB (Fig. 5A, leaf 1 compared with 2), and green fluorescence was detected only in the apoplast of ToxB-488 treated wheat leaves 3, 8, and $24 \mathrm{~h}$ after treatment (Fig. 5B). The green fluorescent signal was less easily imaged at $24 \mathrm{~h}$, which suggests some ToxB-488 protein degradation, diffusion, or signal quenching by this time.
In the apoplast only, the pattern of ToxB-488 detection was different from the detection pattern of free Alexa Fluor 488 and ToxA-488. Free Alexa Fluor 488 infiltrated at a concentration such that the intensity of fluorescent tag was equal to the intensity of fluorescence present in the ToxB-488 samples and was easily visualized within mesophyll cells and localized to the vacuole and the cytosol. The intracellular free Alexa Fluor 488 fluorescent signal was strong, rapidly detected, and persisted for at least $24 \mathrm{~h}$ (data not shown). The detection of ToxB-488 only in the apoplast at 3,8 , and $24 \mathrm{~h}$ following infiltration was also different than the initial cytoplasmic $(5 \mathrm{~h}$ post-treatment) and eventual chloroplastic detection ( $8 \mathrm{~h}$ posttreatment) of fluorescence due to treatment of sensitive wheat leaves with ToxA-488. Taken together, these results indicate that, in contrast to ToxA, ToxB appears to remain in the apoplast and that one or more mechanisms by which this toxin triggers cell death must involve a protein partner present either in the apoplast or at the cell wall-plasma membrane interface.

\section{DISCUSSION}

Apoplastic effectors are typically small molecules with conformational stability that allows them to survive in an acidic environment rich in plant-secreted proteases, defense enzymes, and antimicrobial compounds (Felle 1998; Göhre and Robatzek 2008; Rep 2005). The conformational stability of apoplastic effectors is often dictated by the presence of disulfide bridges between cysteine residues (Rep 2005; Stergiopoulos and de Wit 2009). ToxB and its inactive form toxb are both small proteins ( 6.5 and $6.6 \mathrm{kDa}$, respectively) with four cysteine residues responsible for the formation of two disulfide bridges (Figueroa Betts et al. 2011; Nyarko et al. 2014). The lack of degradation of ToxB by apoplastic proteases present in AF extracted from two different wheat cultivars showed that ToxB is more resistant to proteolysis than ToxA, an intracellular-acting HST (Fig. 3). Recent NMR studies of ToxB and toxb indicate that both proteins share a similar compact structure with $\beta$-sandwich topology and the same disulfide-bridging pattern (Nyarko et al. 2014); thus, the resistance to apoplastic proteases of both proteins is not a surprising result. The ability to displace ToxBinduced symptoms by hydraulic pressure (Fig. 2) and recover ToxB from AF following ToxB infiltration (Fig. 3) is also consistent with the presence of ToxB in the apoplast. The tolerance of ToxB to heat and organic compounds (Orolaza et al. 1995; Strelkov et al. 1999) in combination with the compact and rigid structure of the toxin (Nyarko et al. 2014) suggests that ToxB has the physical properties that would allow it to survive in the environment of the apoplastic space. Finally, the reduction of symptom development due to treatment with a strong proteolytic cocktail as late as $8 \mathrm{~h}$ post-toxin treatment (Fig. 4) suggests ToxB-induced symptoms are a consequence of an interaction between ToxB and one or more putative extracellular interacting proteins in the plant. Comparison of the structures of ToxB and toxb supports the idea that the interaction between ToxB and a putative partner protein is an important aspect of the underlying mechanism employed by ToxB to trigger chlorosis. While both proteins have nearly identical structures, polymorphisms in the N-termini of the proteins cause a difference in a solvent-exposed loop region and increase the flexibility in one sandwich half of toxb, causing a more expanded structure near the $\mathrm{Cys}^{18}$ and $\mathrm{Cys}^{64}$ disulfide bridge (Nyarko et al. 2014). Such structural changes likely impact function by altering the binding specificity with one or more other proteins. The importance of proper protein folding and the resultant inability to interact with a putative partner may explain the lack of symptom development in the BSMV-mediated transient expression of an $\mathrm{N}$-terminal ToxB 
protein fusion. This interpretation is supported by in vitro assessment of toxic activity of ToxB protein fusions that led to ambiguous results. While our data support the hypothesis that ToxB exerts its activity as an apoplastic effector, there is an alternative interpretation that cannot be ruled out. Slow uptake of ToxB may explain the results obtained by hydraulic pressure and pronase degradation. Furthermore, fluorescent microscopy has sensitivity limitations, and although ToxA was clearly detected inside the cells, it is possible that ToxB is internalized in small quantities at a very slow rate that may be difficult to capture by imaging techniques.

The apoplastic space contains proteases, cell wall-degrading enzymes, and hydrolases among other enzymes that can hinder

A

Pronase treatment $(\mathrm{mg} / \mathrm{ml})$

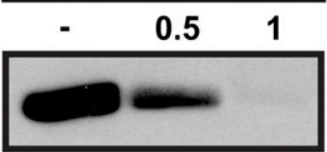

B

Step 1

ToxB infiltration

Wheat leaf

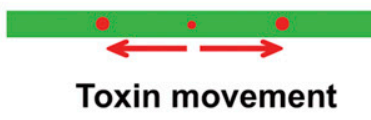

Step 2

Pronase infiltration

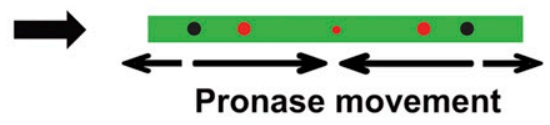

C

Treatments

\begin{tabular}{c|c|c|}
\hline Step 1 (ToxB) & Step 2 (Pronase) & \\
\hline- & - & a \\
- & + & b \\
+ & - & c \\
+ & $1 \mathrm{hpi}$ & $\mathrm{d}$ \\
+ & $3 \mathrm{hpi}$ & $\mathrm{e}$ \\
+ & $6 \mathrm{hpi}$ & $\mathrm{f}$ \\
+ & $8 \mathrm{hpi}$ & $\mathrm{g}$ \\
+ & $24 \mathrm{hpi}$ & $\mathrm{h}$ \\
+ & $48 \mathrm{hpi}$ & $\mathrm{i}$
\end{tabular}

D

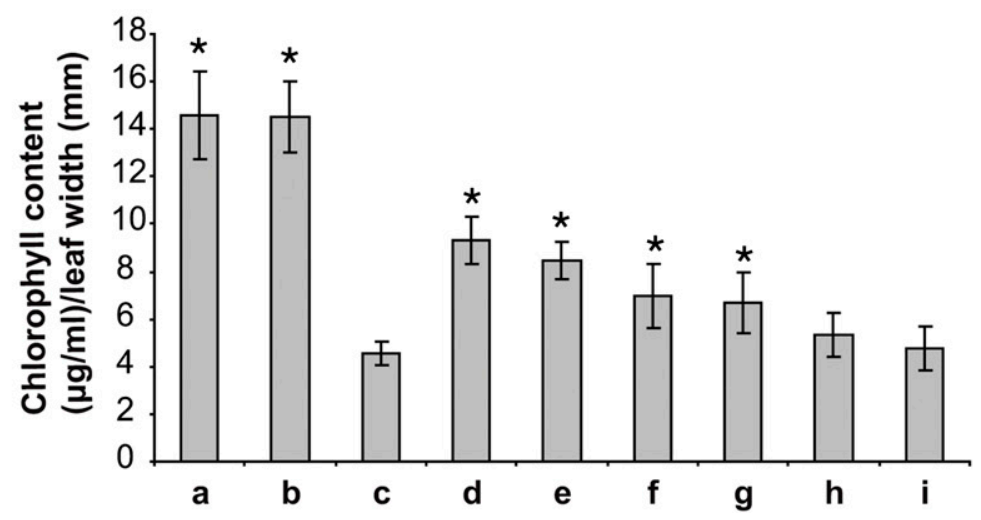

Fig. 4. Protease treatment reduces ToxB-induced symptoms. A, Western blot of in vitro digestion of $10 \mu \mathrm{M}$ ToxB with 0.5 and $1 \mathrm{mg}$ of pronase per milliliter for 30 min. Immunoblot was probed with anti-Ptr ToxB antisera. B, Experimental design. Step 1, infiltration with either $10 \mu \mathrm{M}$ ToxB or $\mathrm{H}_{2} \mathrm{O}$ alone (red dots). Step 2 , infiltration with $1 \mathrm{mg}$ of pronase per milliliter at the toxin infiltration zone (black dots). $\mathbf{C}$, Bioassay of toxin-sensitive wheat leaves treated with $\mathrm{H}_{2} \mathrm{O}$ alone (leaf a), pronase alone (leaf b), ToxB alone (leaf c), or ToxB followed by pronase at 1, 3, 6, 8, 24, and $48 \mathrm{~h}$ post-toxin infiltration (hpi) (leaves $\mathrm{d}$ to i): + and refer to presence or absence of treatment, respectively. D, Total chlorophyll quantification assay of infiltrated leaf area according to treatments described in panel C. Bars indicate the mean of three independent experiments. Error bars represent standard error. Asterisks $(*)$ indicate treatments that are significantly different from ToxB treatment as determined by Student's $t$ test $(P<0.05)$. 
the pathogen's survival (Hückelhoven 2007). Pathogens have evolved to synthesize proteins to defend themselves against such harmful enzymes. Research on plant pathogens such as Cladosporium fulvum, the causal agent of leaf mold of tomato, and Phytophthora infestans, the causal agent of late blight in tomato and potato, has contributed significantly to the understanding of the role of small secreted proteins and the diverse mechanisms that a pathogen can exploit to survive in the
A

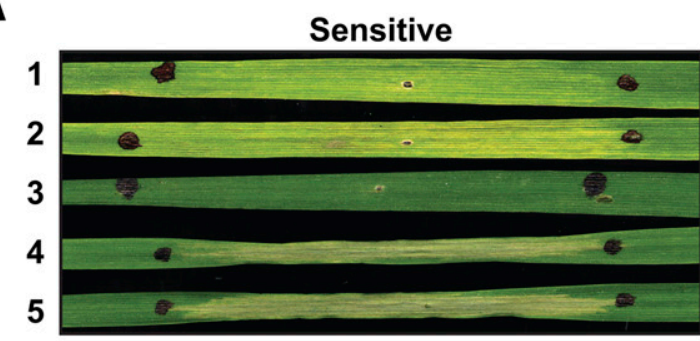

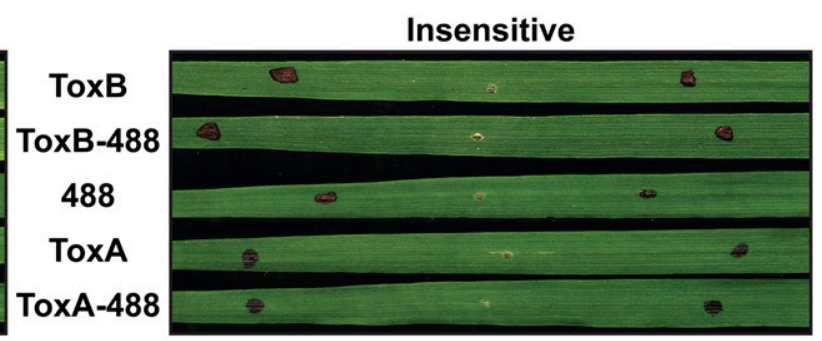

B

Sensitive
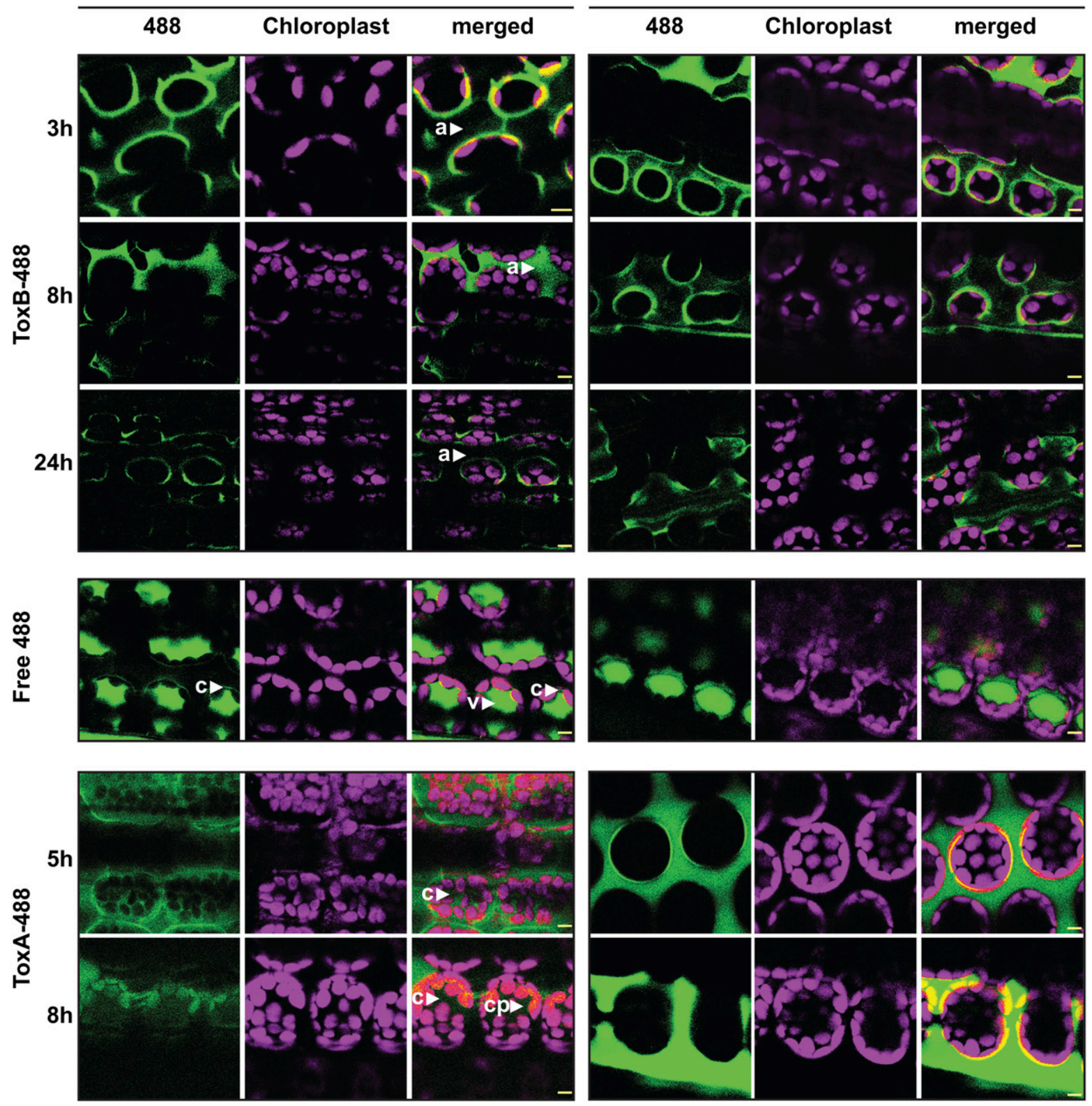

Fig. 5. Fluorescently labeled ToxB is detectable only in the wheat leaf apoplast. A, Bioassay of toxin-sensitive (Katepwa) and -insensitive (Auburn) wheat cultivars treated with Alexa Fluor 488 unlabeled (1 and 4) and labeled (2 and 5) ToxB (1 and 2) and ToxA (4 and 5) and free Alexa Fluor 488 dye (3). Leaves were collected 5 days after infiltration. B, Confocal microscopy of toxin-sensitive and -insensitive live wheat leaves treated with Alexa Fluor 488-labeled ToxB, ToxA, or free Alexa Fluor 488. Leaves were imaged in two channels to detect fluorescence of Alexa Fluor 488 (left panel, green), chloroplast autofluroescence (center panel, magenta), and these signals merged into a single image (right panel). Green fluorescence (arrowhead) could be detected in the apoplast (a), vacuole (v), cytosol (c), or chloroplast (cp), depending upon the treatment. Scale bars $=5 \mu \mathrm{m}$. 
apoplast and evade plant recognition. $C$. fulvum releases chitinbinding effectors such as Ecp6, which masks chitin oligosaccharides preventing activation of plant immunity (de Jonge and Thomma 2009, 2010), or Avr4, which binds to the fungal cell wall and protects it against degradation by chitinases (Joosten et al. 1994; van den Burg et al. 2006; van Esse et al. 2007). The inhibition of host proteases appears to be another common mechanism utilized by plant pathogens. C. fulvum releases the cysteine protease inhibitor Avr2 into the apoplast, which impairs the Rcr-3, PIP1, and other essential components for basal host defense (Krüger et al. 2002; Luderer et al. 2002; Rooney et al. 2005; Shabab et al. 2008; Song et al. 2009; van Esse et al. 2008). The oomycete Phytophthora infestans provides additional examples of the role of protease inhibitors in pathogenicity (Tian et al. 2004a and b, 2005, 2007).

The multicopy nature of ToxB, the existence of toxb in P. tritici-repentis, and the presence of ToxB homologs in other ascomycetes (Andrie and Ciuffetti 2011; Andrie et al. 2008; Martinez et al. 2001, 2004; Strelkov et al. 1999, 2006) suggest that ToxB could have functions other than that of a chlorosisinducing toxin (Amaike et al. 2008; Ciuffetti et al. 2010). Interestingly, silencing of ToxB in $P$. tritici-repentis reduces the ability to induce chlorosis and the number of appressoria formed compared with wild-type strains (Aboukhaddour et al. 2012). Thus, ToxB appears to play an important role during the early stages of infection that may or may not involve plant responses. It is possible that, in addition to functions in morphogenesis and development, ToxB fulfills other biological functions related to its extracellular site of action and, perhaps, the survival of the pathogen in the apoplastic space.

Several HST have been identified in Stagonospora nodorum, an important wheat pathogen that is closely related to $P$. triticirepentis. Similar to ToxB, some of these toxins, such as SnTox 3 and SnTox1 (Liu et al. 2009 and 2012, respectively), are small proteins with high cysteine content. Interestingly, SnTox1 appears to play a role during plant penetration (Liu et al. 2009). Recent map-based cloning of Snnl, which confers sensitivity to SnTox1, suggests that Snn1 encodes a wall-associated kinase (Faris et al. 2014) and strengthens the hypothesis that SnTox 1 functions in the apoplast (Liu et al. 2012). The ToxB sensitivity gene Tsc2 (Friesen and Faris 2004) has not been cloned yet and, so far, no interacting partners of ToxB have been identified. Such discoveries will provide insight into the possible functions of this toxin and may allow identification of similarities to other fungal effectors.

ToxA-induced symptoms are first detected at $14 \mathrm{hpi}$, whereas ToxB-induced symptoms become visible after 48 hpi (Kim et al. 2010; Pandelova et al. 2009, 2012). Comparative transcriptome analyses between ToxA and ToxB indicate that the later onset of ToxB-induced symptom development correlates with a delay in transcriptional and biochemical responses (Pandelova et al. 2012). While ToxA induces massive transcriptional reprogramming at 3 hpi (Pandelova et al. 2009), significant ToxB-induced transcriptional changes were not detected until 9 hpi (Pandelova et al. 2012). The requirement of an extended interaction (approximately $8 \mathrm{~h}$ ) between ToxB and a sensitive plant cell to induce full symptom development correlates with the delayed onset of the ToxB-induced transcriptional changes. Thus, the distinctive extracellular versus intracellular site of action of ToxB and ToxA, respectively, could explain the difference in the onset of transcriptional reprogramming in response to these toxins. Similar to ToxA, ToxB induces defense responses, reactive oxygen species accumulation, and photosystem disfunction (Kim and Strelkov 2007; Pandelova et al. 2012; Strelkov et al. 1999). An apoplastic site of action of ToxB raises questions about the mechanism by which an extracellular toxin can activate pathways in a manner that resembles the mechanism of action of intracellularly acting ToxA. One possibility is that the interaction between ToxB and one or more protein partners present at the apoplast or cell wall-plasma membrane interface, either direct or mediated by a protein complex, results in the activation of a signaling cascade that eventually converges with pathways also activated by ToxA. In summary, the findings presented here suggest that ToxB acts as an extracellular effector. This is a significant step toward understanding the role of this toxin in disease susceptibility and demonstrates the diversity of the mechanisms of action of HST in P. tritici-repentis.

\section{MATERIALS AND METHODS}

\section{Bioassays.}

Plant growth and maintenance were performed as described previously (Manning et al. 2004). All bioassays were carried out using heterologously expressed toxins (Figueroa Betts et al. 2011). Leaves were infiltrated with $10 \mu \mathrm{M}$ ToxB unless indicated differently. All treatments were performed on secondary leaves of 2-week old plants. To document symptom development, the leaves were evaluated 5 days post-toxin infiltration and were scanned with an Epson scanner (Epson America, Long Beach, CA, U.S.A.). Experiments were repeated at least three times with similar results.

To evaluate hydraulic pressure-induced displacement of toxin-induced symptoms, five toxin-sensitive leaves were infiltrated with ToxB, followed by infiltration with doubledistilled $\mathrm{H}_{2} \mathrm{O}$ (for simplicity, referred to as $\mathrm{H}_{2} \mathrm{O}$ ). The toxininfiltration zone covered an approximately $4-\mathrm{cm}$ section of the leaf. Infiltration of $\mathrm{H}_{2} \mathrm{O}$ was carried out at the toxin infiltration point and extended at least $1 \mathrm{~cm}$ beyond the toxin infiltration zone. Experiments were repeated at least three times with similar results. Colorization of ToxB-induced chlorosis in Figure 2 was performed in Adobe Photoshop CS3 software by defining the chlorotic tissue using the color range function (under select). Selection of the chlorotic area was done with the eyedropper tool, and the fuzziness option was adjusted to ensure inclusion of only chlorotic tissue.

In vitro digestions of $10 \mu \mathrm{M}$ ToxB with pronase (SigmaAldrich, St. Louis) at concentrations of 0.5 and $1 \mathrm{mg} / \mathrm{ml}$ were performed at room temperature for $30 \mathrm{~min}(45 \mu \mathrm{l})$. Protease treatments of ToxB-infiltrated leaves included infiltration of eight toxin-sensitive leaves with ToxB alone or ToxB followed by a treatment with $1 \mathrm{mg}$ of pronase per milliliter. Plants were returned to the growth chamber to allow symptom development. Chlorophyll extraction and quantification was conducted as described by Manning et al. (2009), with the following modifications, a $3-\mathrm{cm}$ section from the center of the toxin infiltration zone was cut in $0.5-\mathrm{cm}$ pieces and the leaf slices were placed in $2 \mathrm{ml}$ of $100 \%$ methanol for 2 days at room temperature under dark conditions. Experiments were repeated at least three times with similar results.

\section{Purification and detection of heterologously expressed proteins.}

Purification of heterologous proteins ToxB and toxb was conducted as described by Figueroa Betts et al. (2011). Histagged ToxA production followed the protocols described by Manning et al. (2004). Protein concentration was measured with the Pierce BCA protein assay kit (Pierce, Rockford, IL, U.S.A.), using bovine serum albumin as a standard. Proteins were detected by either silver staining of $14 \%$ acrylamide SDSPAGE gel (Fling and Gregerson 1986), Western blot (Silver Snap II; Thermo Scientific-Pierce, Rockford, IL, U.S.A.), or both. Western blot analysis for ToxA and ToxB/toxb was carried out as described by Manning and Ciuffetti (2005) and 
Andrie and Ciuffetti (2011), respectively. Blots were developed using chemiluminescent SuperSignal West Dura extended duration substrate (Thermo Scientific-Pierce) following the manufacturer's instructions. Analyses were repeated at least three times with similar results.

\section{Experiments with apoplastic fluid from wheat leaves.}

To extract AF, leaves were infiltrated with $\mathrm{H}_{2} \mathrm{O}$, and a $3-\mathrm{cm}$ water-treated leaf section was removed, cut in half, placed longitudinally in a $0.5-\mathrm{ml}$ Eppendorf tube with a perforated bottom that allowed collection of $\mathrm{AF}$ in a $1.5-\mathrm{ml}$ Eppendorf tube, after centrifugation at $3,000 \times g$ for $15 \mathrm{~min}$ at $4^{\circ} \mathrm{C}$. Eight $3-\mathrm{cm}$ leaf sections yielded approximately $20 \mu \mathrm{l}$ of AF for immediate use in a single experiment. In vitro digestion reactions of His-tagged ToxA, ToxB, and toxb with apoplastic extracts were set up following a ratio of $2.5 \mu \mathrm{mol}$ of protein per microliter of $\mathrm{AF}$ in a total volume of $6 \mu \mathrm{l}$. Digestion reactions were carried out for 1,6 , or $24 \mathrm{~h}$ at room temperature and were adjusted with $\mathrm{H}_{2} \mathrm{O}$ to a final volume of $10 \mu \mathrm{l}$, prior to Western blot analysis. Apoplastic extracts from leaves infiltrated with ToxB were obtained in the same manner with the exception that the ToxB-treated zone was infiltrated with $\mathrm{H}_{2} \mathrm{O}$ from the left and right flanking sides of the toxin infiltration zone to prevent the toxin from being displaced from the treatment zone.

\section{Fluorescent labeling and confocal microscopy.}

Heterologously expressed ToxB and His-ToxA were labeled with the Alexa Fluor 488 microscale protein labeling kit (Life Technologies, Grand Island, NY, U.S.A.), following manufacturer's instructions. Fifty microliters of $3-\mathrm{mg} / \mathrm{ml}$ ToxB and $1.8-\mathrm{mg} / \mathrm{ml}$ His-ToxA were labeled with 6.8 and $7.6 \mu \mathrm{l}$ of reactive Alexa Fluor 488 dye, respectively, for $30 \mathrm{~min}$. The degree of labeling (DOL) of each Alexa Fluor 488 dye-labeled protein conjugate was determined according to the manufacturer's protocol. The DOL for ToxB-488 and His-ToxA was 0.3 and 4.5, respectively. Free Alexa Fluor 488 for infiltration was prepared by adding $2.4 \mu \mathrm{l}$ of reactive dye to $100 \mu \mathrm{l}$ of $0.1-\mathrm{M}$ sodium bicarbonate. A similar level of activity for unlabeled and labeled toxin (10 and $2 \mu \mathrm{M}$ for ToxB and ToxA, respectively) was confirmed by infiltration into toxin-sensitive and -insensitive cultivars. Confocal microscopy was performed on live tissue as previously described (Manning \& Ciuffetti 2005). For imaging, $50 \mu \mathrm{M}$ ToxB-488, $5 \mu \mathrm{M}$ His-ToxA-488, and an absorption at $494 \mathrm{~nm}$ of 2.3 of free Alexa Flour 488 were infiltrated as previously described.

\section{ACKNOWLEDGMENTS}

This research was supported by a National Science Foundation Postdoctoral Fellowship (award 0706881 to M. Figueroa) and in part by the Agriculture and Food Research Initiative Competitive Grants Program (grant number 2010-65108-20548 to L. M. Ciuffetti) from the United States Department of Agriculture National Institute of Food and Agriculture. We thank A. Chu, E. Perez, and T. Holman for technical assistance.

\section{LITERATURE CITED}

Aboukhaddour, R., Kim, Y. M., and Strelkov, S. E. 2012. RNA-mediated gene silencing of ToxB in Pyrenophora tritici-repentis. Mol. Plant Pathol. 13:318-326.

Amaike, S., Ozga, J. A., Basu, U., and Strelkov, S. E. 2008. Quantification of ToxB gene expression and formation of appressoria by isolates of Pyrenophora tritici-repentis differing in pathogenicity. Plant Pathol. 57: 623-633.

Andrie, R. M., and Ciuffetti, L. M. 2011. Pyrenophora bromi, causal agent of brownspot of bromegrass, expresses a gene encoding a protein with homology and similar activity to Ptr ToxB, a host-selective toxin of wheat. Mol. Plant-Microbe Interact. 24:359-367.
Andrie, R. M., Schoch, C. L., Hedges, R., Spatafora, J. W., and Ciuffetti, L. M. 2008. Homologs of ToxB, a host-selective toxin gene from Pyrenophora tritici-repentis, are present in the genome of sister-species Pyrenophora bromi and other members of the Ascomycota. Fungal Genet. Biol. 45:363-377

Ballance, G. M., Lamari, L., and Bernier, C. C. 1989. Purification and characterization of a host-selective necrosis toxin from Pyrenophora tritici-repentis. Physiol. Mol. Plant Pathol. 35:203-213.

Brown, D. A., and Hunger, R. M. 1993. Production of a chlorosis-inducing, host-specific, low-molecular-weight toxin by isolates of Pyrenophora tritici-repentis, cause of tan spot of wheat. J. Phytopathology 137: 221-232.

Ciuffetti, L. M., Francl, L. J., Ballance, G. M., Bockus, W. W., Lamari, L., Meinhardt, S. W., and Rasmussen, J. B. 1998. Standardization of toxin nomenclature in the Pyrenophora tritici-repentis/wheat interaction. Can. J. Plant Pathol. 20:421-424.

Ciuffetti, L. M., Manning, V. A., Pandelova, I., Betts, M. F., and Martinez, J. P. 2010. Host-selective toxins, Ptr ToxA and Ptr ToxB, as necrotrophic effectors in the Pyrenophora tritici-repentis-wheat interaction. New Phytol. 187:911-919.

Ciuffetti, L. M., Tuori, R. P., and Gaventa, J. M. 1997. A single gene encodes a selective toxin causal to the development of tan spot of wheat. Plant Cell 9:135-144

de Jonge, R., and Thomma, B. P. 2009. Fungal LysM effectors: Extinguishers of host immunity? Trends Microbiol. 17:151-157.

de Jonge, R., van Esse, H. P., Kombrink, A., Shinya, T., Desaki, Y., Bours, R., van der Krol, S., Shibuya, N., Joosten, M. H., and Thomma, B. P 2010. Conserved fungal LysM effector Ecp6 prevents chitin-triggered immunity in plants. Science 329:953-955.

De Wolf, E. D., Effertz, R. J., Ali, S., and Francl, L. J. 1998. Vistas on tan spot research. Can. J. Plant Pathol. 20:349-444.

Faris, J., Shi, G., Raats, D., Friesen, T., Frenkel, Z., Liu, Z., Brueggeman, R., Rasmussen, J., and Fahima, T. 2014. Map-based cloning of the wheat Snnl gene reveals a wall-associated kinase hijacked by the necrotrophic pathogen Stagonospora nodorum to cause disease. W437. International Plant and Animal Genome Conference XXII, San Diego, CA, U.S.A.

Faris, J. D., Liu, Z., and Xu, S. S. 2013. Genetics of tan spot resistance in wheat. Theor. Appl. Genet. 126:2197-2217.

Felle, H. H. 1998. The apoplastic $\mathrm{pH}$ of the Zea mays root cortex as measured with $\mathrm{pH}$-sensitive microelectrodes: Aspects of regulation. J. Exp. Bot. 49:987-995.

Figueroa Betts, M., Manning, V. A., Cardwell, K. B., Pandelova, I., and Ciuffetti, L. M. 2011. The importance of the N-terminus for activity of Ptr ToxB, a chlorosis-inducing host-selective toxin produced by Pyrenophora tritici-repentis. Physiol. Mol. Plant Pathol. 75:138-145.

Fling, S. P., and Gregerson, D. S. 1986. Peptide and protein molecular weight determination by electrophoresis using a high-molarity tris buffer system without urea. Anal. Biochem. 155:83-88.

Friesen, T. L., and Faris, J. D. 2004. Molecular mapping of resistance to Pyrenophora tritici-repentis race 5 and sensitivity to Ptr ToxB in wheat. Theor. Appl. Genet. 109:464-471.

Friesen, T. L., Faris, J. D., Solomon, P. S., and Oliver, R. P. 2008. Hostspecific toxins: Effectors of necrotrophic pathogenicity. Cell. Microbiol 10:1421-1428.

Göhre, V., and Robatzek, S. 2008. Breaking the barriers: Microbial effector molecules subvert plant immunity. Annu. Rev. Phytopathol. 46:189-215.

Hogenhout, S. A., Van der Hoorn, R. A., Terauchi, R., and Kamoun, S. 2009. Emerging concepts in effector biology of plant-associated organisms. Mol. Plant-Microbe Interact. 22:115-122.

Hückelhoven, R. 2007. Cell wall-associated mechanisms of disease resistance and susceptibility. Annu. Rev. Phytopathol. 45:101-127.

Jones, J. D., and Dangl, J. L. 2006. The plant immune system. Nature 444: 323-329.

Joosten, M., and de Wit, P. 1999. The tomato-Cladosporium fulvum interaction: A versatile experimental system to study plant-pathogen interactions. Annu. Rev. Phytopathol. 37:335-367.

Joosten, M. H., Cozijnsen, T. J., and De Wit, P. J. 1994. Host resistance to a fungal tomato pathogen lost by a single base-pair change in an avirulence gene. Nature 367:384-386.

Kamoun, S. 2006. A catalogue of the effector secretome of plant pathogenic oomycetes. Annu. Rev. Phytopathol. 44:41-60.

Kim, Y. M., Bouras, N., Kav, N. N., and Strelkov, S. E. 2010. Inhibition of photosynthesis and modification of the wheat leaf proteome by $P \operatorname{tr} T o x B$ : A host-specific toxin from the fungal pathogen Pyrenophora triticirepentis. Proteomics 10:2911-2926.

Kim, Y. M., and Strelkov, S. E. 2007. Heterologous expression and activity of Ptr ToxB from virulent and avirulent isolates of Pyrenophora triticirepentis. Can. J. Plant Pathol. 29:232-242. 
Krüger, J., Thomas, C. M., Golstein, C., Dixon, M. S., Smoker, M., Tang, S., Mulder, L., and Jones, J. D. 2002. A tomato cysteine protease required for Cf-2-dependent disease resistance and suppression of autonecrosis. Science 296:744-747.

Lamari, L., Ballance, G. M., Orolaza, N. P., and Kowatsch, R. 1995. In planta production and antibody neutralization of the Ptr necrosis toxin from Pyrenophora tritici-repentis. Phytopathology 85:333-338.

Liu, Z., Faris, J. D., Oliver, R. P., Tan, K.-C., Solomon, P. S., McDonald, M. C., McDonald, B. A., Nunez, A., Lu, S., Rasmussen, J. B., and Friesen, T. L. 2009. SnTox3 acts in effector triggered susceptibility to induce disease on wheat carrying the Snn3 gene. PLoS Pathog. 5:e1000581.

Liu, Z., Zhang, Z., Faris, J. D., Oliver, R. P., Syme, R., McDonald, M. C., McDonald, B. A., Solomon, P. S., Lu, S., Shelver, W. L., Xu, S., and Friesen, T. L. 2012. The cysteine rich necrotrophic effector SnTox1 produced by Stagonospora nodorum triggers susceptibility of wheat lines harboring Snn1. PLoS Pathog. 8:e1002467.

Luderer, R., Takken, F. L., de Wit, P. J., and Joosten, M. H. 2002. Cladosporium fulvum overcomes $\mathrm{Cf}$-2-mediated resistance by producing truncated AVR2 elicitor proteins. Mol. Microbiol. 45:875-884.

Manning, V. A., Andrie, R. M., Trippe, A. F., and Ciuffetti, L. M. 2004. Ptr ToxA requires multiple motifs for complete activity. Mol. Plant-Microbe Interact. 17:491-501.

Manning, V. A., Chu, A. L., Scofield, S. R., and Ciuffetti, L. M. 2010. Intracellular expression of a host-selective toxin, ToxA, in diverse plants phenocopies silencing of a ToxA-interacting protein, ToxABP1. New Phytol. 187:1034-1047.

Manning, V. A., Chu, A. L., Steeves, J. E., Wolpert, T. J., and Ciuffetti, L. M. 2009. A host-selective toxin of Pyrenophora tritici-repentis, Ptr ToxA, induces photosystem changes and reactive oxygen species accumulation in sensitive wheat. Mol. Plant-Microbe Interact. 22: 665-676.

Manning, V. A., and Ciuffetti, L. M. 2005. Localization of Ptr ToxA produced by Pyrenophora tritici-repentis reveals protein import into wheat mesophyll cells. Plant Cell 17:3203-3212.

Manning, V. A., Hamilton, S. M., Karplus, P. A., and Ciuffetti, L. M. 2008. The Arg-Gly-Asp-containing, solvent-exposed loop of Ptr ToxA is required for internalization. Mol. Plant-Microbe Interact. 21:315-325.

Martinez, J. P., Oesch, N. W., and Ciuffetti, L. M. 2004. Characterization of the multiple-copy host-selective toxin gene, ToxB, in pathogenic and nonpathogenic isolates of Pyrenophora tritici-repentis. Mol. PlantMicrobe Interact. 17:467-474.

Martinez, J. P., Ottum, S. A., Ali, S., Franci, L. J., and Ciuffetti, L. M. 2001. Characterization of the ToxB gene from Pyrenophora tritici-repentis. Mol. Plant-Microbe Interact. 14:675-677.

Murray, G. M., and Brennan, J. P. 2009. Estimating disease losses to the Australian wheat industry. Australasian Plant Pathol. 38:558-570.

Narahashi, Y. 1970. Pronase. Methods Enzymol. 19:651-664.

Nyarko, A., Singarapu, K. K., Figueroa, M., Manning, V. A., Pandelova, I., Wolpert, T. J., Ciuffetti, L. M., and Barbar, E. 2014. Solution NMR structures of active Pyrenophora tritici-repentis ToxB and its inactive homolog reveal potential determinants of toxin activity. J. Biol. Chem. 289:25946-25956.

Orolaza, N. P., Lamari, L., and Ballance, G. M. 1995. Evidence of a hostspecific chlorosis toxin from Pyrenophora tritici-repentis, the causal agent of tan spot of wheat. Phytopathology 85:1282-1287.

Pandelova, I., Betts, M. F., Manning, V. A., Wilhelm, L. J., Mockler, T. C., and Ciuffetti, L. M. 2009. Analysis of transcriptome changes induced by Ptr ToxA in wheat provides insights into the mechanisms of plant susceptibility. Mol. Plant 2:1067-1083.

Pandelova, I., Figueroa, M., Wilhelm, L. J., Mankaney, A. N., Mockler, T. C., and Ciuffetti, L. M. 2012. Comparative analysis of transcriptome changes induced in sensitive wheat by the host-selective toxins, Ptr ToxB and Ptr ToxA, produced by Pyrenophora tritici-repentis. PLoS One 7: e40240.

Perello, A., Moreno, V., Simon, M. R., and Sisterna, M. 2003. Tan spot of wheat infection at different stages of crop development and inoculum type. Crop Prot. 22:157-169.

Rep, M. 2005. Small proteins of plant-pathogenic fungi secreted during host colonization. FEMS Microbiol. Lett. 253:19-27.

Rooney, H. C., Van't Klooster, J. W., van der Hoorn, R. A., Joosten, M. H., Jones, J. D., and de Wit, P. J. 2005. Cladosporium Avr2 inhibits tomato $\mathrm{Rcr} 3$ protease required for $\mathrm{Cf}-2$-dependent disease resistance. Science 308:1783-1786.
Sarma, G. N., Manning, V. A., Ciuffetti, L. M., and Karplus, P. A. 2005 Structure of Ptr ToxA: An RGD-containing host-selective toxin from Pyrenophora tritici-repentis. Plant Cell 17:3190-3202.

Shabab, M., Shindo, T., Gu, C., Kaschani, F., Pansuriya, T., Chintha, R., Harzen, A., Colby, T., Kamoun, S., and van der Hoorn, R. A. 2008 Fungal effector protein AVR2 targets diversifying defense-related cys proteases of tomato. Plant Cell 20:1169-1183.

Song, J., Win, J., Tian, M., Schornack, S., Kaschani, F., Ilyas, M., van der Hoorn, R. A., and Kamoun, S. 2009. Apoplastic effectors secreted by two unrelated eukaryotic plant pathogens target the tomato defense protease Rcr3. Proc. Natl. Acad. Sci. U.S.A. 106:1654-1659.

Stergiopoulos, I., and de Wit, P. J. 2009. Fungal effector proteins. Annu. Rev. Phytopathol. 47:233-263.

Strelkov, S. E., Kowatsch, R. F., Ballance, G. M., and Lamari, L. 2006. Characterization of the ToxB gene from North African and Canadian isolates of Pyrenophora tritici-repentis. Physiol. Mol. Plant Pathol. 67: 164-170.

Strelkov, S. E., and Lamari, L. 2003. Host-parasite interaction in tan spot [Pyrenophora tritici-repentis] of wheat. Can. J. Plant Pathol. 25:339-349.

Strelkov, S. E., Lamari, L., and Ballance, G. M. 1999. Characterization of a host-specific protein toxin (Ptr ToxB) from Pyrenophora triticirepentis. Mol. Plant-Microbe Interact. 12:728-732.

Thomma, B. P., VAN Esse, H. P., Crous, P. W., and DE Wit, P. J. 2005. Cladosporium fulvum (syn. Passalora fulva), a highly specialized plant pathogen as a model for functional studies on plant pathogenic Mycosphaerellaceae. Mol. Plant Pathol. 6:379-393.

Tian, M., Benedetti, B., and Kamoun, S. 2005. A second Kazal-like protease inhibitor from Phytophthora infestans inhibits and interacts with the apoplastic pathogenesis-related protease P69B of tomato. Plant Physiol. 138:1785-1793.

Tian, M., Champouret, N., and Kamoun, S. 2004a. Extracellular protease inhibitors of Phytophthora infestans determine a novel counterdefense mechanism. Phytopathology 94:S136.

Tian, M., Huitema, E., Da Cunha, L., Torto-Alalibo, T., and Kamoun, S. 2004b. A Kazal-like extracellular serine protease inhibitor from Phytophthora infestans targets the tomato pathogenesis-related protease P69B. J. Biol. Chem. 279:26370-26377.

Tian, M., Win, J., Song, J., van der Hoorn, R., van der Knaap, E., and Kamoun, S. 2007. A Phytophthora infestans cystatin-like protein targets a novel tomato papain-like apoplastic protease. Plant Physiol. 143: 364-377.

Tomas, A., Feng, G. H., Reeck, G. R., Bockus, W. W., and Leach, J. E. 1990. Purification of a cultivar-specific toxin from Pyrenophora triticirepentis, causal agent of tan spot of wheat. Mol. Plant-Microbe Interact 3:221-224.

Trop, M., and Birk, Y. 1970. The specificity of proteinases from Streptomyces griseus (pronase). Biochem. J. 116:19-25.

Tuori, R. P., Wolpert, T. J., and Ciuffetti, L. M. 1995. Purification and immunological characterization of toxic components from cultures of Pyrenophora tritici-repentis. Mol. Plant-Microbe Interact. 8:41-48.

van den Burg, H. A., Harrison, S. J., Joosten, M. H., Vervoort, J., and de Wit, P. J. 2006. Cladosporium fulvum Avr4 protects fungal cell walls against hydrolysis by plant chitinases accumulating during infection. Mol. Plant-Microbe Interact. 19:1420-1430.

van Esse, H. P., Bolton, M. D., Stergiopoulos, I., de Wit, P. J. G. M., and Thomma, B. P. 2007. The chitin-binding Cladosporium fulvum effector protein Avr4 is a virulence factor. Mol. Plant-Microbe Interact. 20: 1092-1101

van Esse, H. P., Van’t Klooster, J. W., Bolton, M. D., Yadeta, K. A., van Baarlen, P., Boeren, S., Vervoort, J., de Wit, P. J., and Thomma, B. P 2008. The Cladosporium fulvum virulence protein Avr2 inhibits host proteases required for basal defense. Plant Cell 20:1948-1963.

Walton, J. D. 1996. Host-selective toxins: Agents of compatibility. Plant Cell 8:1723-1733.

Win, J., Chaparro-Garcia, A., Belhaj, K., Saunders, D. G., Yoshida, K., Dong, S., Schornack, S., Zipfel, C., Robatzek, S., Hogenhout, S. A., and Kamoun, S. 2012. Effector biology of plant-associated organisms: Concepts and perspectives. Cold Spring Harb. Symp. Quant. Biol. 77: 235-247.

Wolpert, T. J., Dunkle, L. D., and Ciuffetti, L. M. 2002. Host-selective toxins and avirulence determinants: What's in a name? Annu. Rev. Phytopathol. 40:251-285.

Zhang, H. F., Francl, L. J., Jordahl, J. G., and Meinhardt, S. W. 1997. Structural and physical properties of a necrosis-inducing toxin from Pyrenophora tritici-repentis. Phytopathology 87:154-160. 